Arq. Bras. Med. Vet. Zootec., v.70, n.3, p.675-681, 2018

\title{
Zygomatic arch fracture in a dog treated with Veterinary Cuttable Plate - case report
}

[Fratura de arco zigomático em um cão tratado com placa veterinária cortável - relato de caso]

\author{
A.S. Macedo ${ }^{1}$, N.M.M. Moens ${ }^{2}$ \\ ${ }^{1}$ Universidade de São Paulo - FMVZ-USP, São Paulo, SP, Brasil \\ ${ }^{2}$ University of Guelph - Guelph, ON, Canada
}

\begin{abstract}
The purpose of this paper is to describe a case of a right zygomatic arch fracture in a 5-year-old male Labrador Retriever diagnosed with aid of 3D Computed Tomography reconstruction. Because of the depressed fracture and interference with the eyeball, surgical repair of the right zygomatic arch fracture was performed with open reduction and stabilization with an 11-hole, $2.7 \mathrm{~mm}$ Veterinary Cuttable Plate. Radiographs taken 60 days after surgery revealed that fracture healing occurred without complications with improved function and cosmetic appearance. Ninety days after surgery the patient was clinically discharged.
\end{abstract}

Keywords: veterinary orthopedics, facial injury, computed tomography, canine

\section{RESUMO}

O objetivo deste trabalho é descrever um caso de fratura do arco zigomático direito em um Labrador Retriever, macho, de cinco anos de idade, diagnosticado com reconstrução $3 D$ de tomografia computadorizada. Devido à depressão da fratura e à interferência com o globo ocular, reparação cirúrgica da fratura do arco zigomático direito foi realizada com redução aberta e estabilização com uma placa veterinária cortável de 2,7mm e 11 orifícios. As radiografias realizadas 60 dias após a cirurgia revelaram que a consolidação óssea ocorreu sem complicações, com melhor funcionalidade e aparência estética. Noventa dias após a cirurgia, o paciente teve alta clínica.

Palavras-chave: ortopedia veterinária, lesão facial, tomografia computadorizada, canino

\section{INTRODUCTION}

Skull fractures in dogs can be related to concurrent trauma to the brain, eyes, and both oral and nasal cavities and may result in loss of support for the orbit, damage to the eye or associated structures (Gruss, 1990). The zygomatic arch is constituted cranially by the zygomatic bone and by the zygomatic process of the temporal bone caudally and gives lateral contour to the face and protects important glandular and neurovascular structures. Cranially, the zygomatic arch contributes to the ventral and lateral rim of the orbit (Newton, 1985). The central structure of the zygomatic arch passes lateral to the vertical ramus of the mandible and if fractured may depress into the mandible and alter mastication while caudal fractures may interfere with the function of the mandibular condyles (Boudrieau \& Kudisch, 1996). For many years, the only diagnostic imaging modality available to assess animals with maxillofacial fractures was conventional radiographic exam; however, the skull is a difficult area to study radiographically due to its very complex bone structure which leads to superimposition of important structures and makes detailed examination of individual parts difficult. Nowadays, computed tomography (CT) has become more available to veterinarians and more affordable to pets owners (Bar-Am et al., 2008). Dissatisfactory imaging could lead to improper diagnosis, lack of or incorrect treatment, which could be pernicious to the patient's restoration of function and cosmetic appearance (Boudrieau, 2005). Although non

Recebido em 23 de janeiro de 2017

Aceito em 11 de outubro de 2017

E-mail: limacedo@gmail.com 
displaced zygomatic fractures can often be treated conservatively, depressed fractures and those compromising function or threatening ocular or neurovascular structures should be reduced and stabilized (Boudrieau, 2012). Many different surgical implants can be used to repair those fractures (Boudrieau, 2005). This paper reports a case of right zygomatic arch fracture in a 5-year-old male Labrador Retriever, diagnosed through 3D CT reconstruction treated surgically with Veterinary Cuttable Plates.

\section{CASE REPORT}

A 5-year-old intact male Labrador retriever was presented to the Emergency Service for evaluation of suspected facial fractures after rough play with other dogs and facial trauma. Vital parameters were within normal limits. Physical examination revealed moderate deformation of the right side of his face below the eye, at the level of the zygomatic arch. The right eye appeared unharmed although slightly deviated and the nictitans membrane was prolapsed. Positive direct pupillary light and menace responses were observed. Neurological examination of the cranial nerves showed no signs of traumatic brain injury. Abbreviated thoracic and abdominal ultrasounds were negative for effusion in the pericardial-, pleural-, or peritoneal spaces. Quick Assessment Tests (packed cell volume, total solids, blood urea nitrogen) and blood gas analysis were within normal limits. A catheter was aseptically placed into a cephalic vein and the patient was then premedicated with dexmedetomidine $2 \mu \mathrm{g} / \mathrm{kg}$, and hydromorphone $0.04 \mathrm{mg} / \mathrm{kg} / \mathrm{h}$ as Continous Rate Infusion (CRI) intravenously (IV). Propofol $4 \mathrm{mg} / \mathrm{kg}$ was administered IV for the induction of anesthesia and endotracheal intubation. Anesthesia was maintained with isoflurane in $100 \%$ oxygen for head computed tomography (CT). The CT images and 3D reconstruction of the images revealed a segmental fracture of the right maxillary and rostral part of the zygomatic bone with a medially displaced fragment interfering with the eyeball (Figure 1). Additionally, fracture between the mesial and distal roots of the $1^{\text {st }}$ superior molar and absence of the $2^{\text {nd }}$ molar both in the right maxilla were observed. Depressed fracture and interference with the eyeball led to a need for surgical repair of the right zygomatic arch fracture. The patient was placed in left lateral recumbency and the right facial area was clipped and aseptically prepared for surgery. Electrocardiogram, pulse oximetry, capnography, Doppler blood pressure, and arterial blood gases were monitored during anesthesia and crystalloid fluids $10 \mathrm{~mL} / \mathrm{kg}$ per hour and fentanyl $10 / \mu \mathrm{g} / \mathrm{kg} / \mathrm{h}$ were administered IV in CRI throughout surgery. Cefazolin $22 \mathrm{mg} / \mathrm{kg}$, IV was administered $30 \mathrm{~min}$ prior to surgery. A curvilinear incision was made along the zygomatic arch, through the skin and subcutaneous tissues. Using a combination of blunt and sharp dissection the zygomatic arch and the fractures were identified. A small incision was made at the attachment of the masseter muscle to the zygomatic arch at the level of the fractured fragment and a periosteal elevator was carefully placed from ventrally along the medial aspect of the displaced fragment. The elevator was lifted laterally, and the fragment reduced in position. An 11 hole, $2.7 \mathrm{~mm}$ Veterinary Cuttable Plate (VCP) was cut to length and contoured to match the shape of the zygomatic arch. The plate was applied to the bone, using eight $2.7 \mathrm{~mm}$ cortical screws. During placement of the rostral screws, the infraorbital foramen was located by palpation and the screws were oriented to avoid penetration and damage avoid to the neurovascular structures. Although the rostral screws were placed through the maxillary recess dorsal to the tooth roots; care was taken when drilling and measuring the screw to minimize penetration of the nasal or oral cavity. The surgical site was lavaged with sterile saline. The Masseter muscle was reattached to the zygomatic arch and the Platysma muscle was closed with 3-0 polydioxanone suture. The subcutaneous tissues were closed with 4-0 polyglactin and the skin was apposed in a cruciate pattern with 3-0 polypropylene. Postoperative radiographs were taken and revealed reduction, alignment and appropriate positioning of the implants (Figure 2A, 2B). 


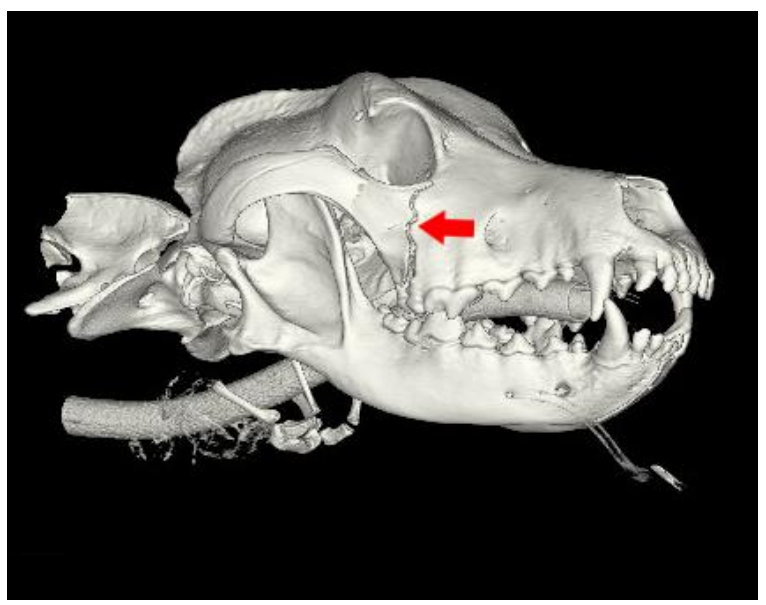

Figure 1. Lateral view of the skull of a 5-year-old male Labrador. It is possible to note a minimally displaced fracture which extends from the rostromedial aspect of the zygomatic bone, between the mesial and distal roots of the 1st superior molar and to the caudolateral aspect of the right maxillary bone (arrow) and a mildly comminuted fracture within the zygomatic bone. The rostral aspect of the right zygomatic bone is mildly displaced medially resulting in mild compression of the ventrolateral aspect of the globe and narrowing of the orbit.
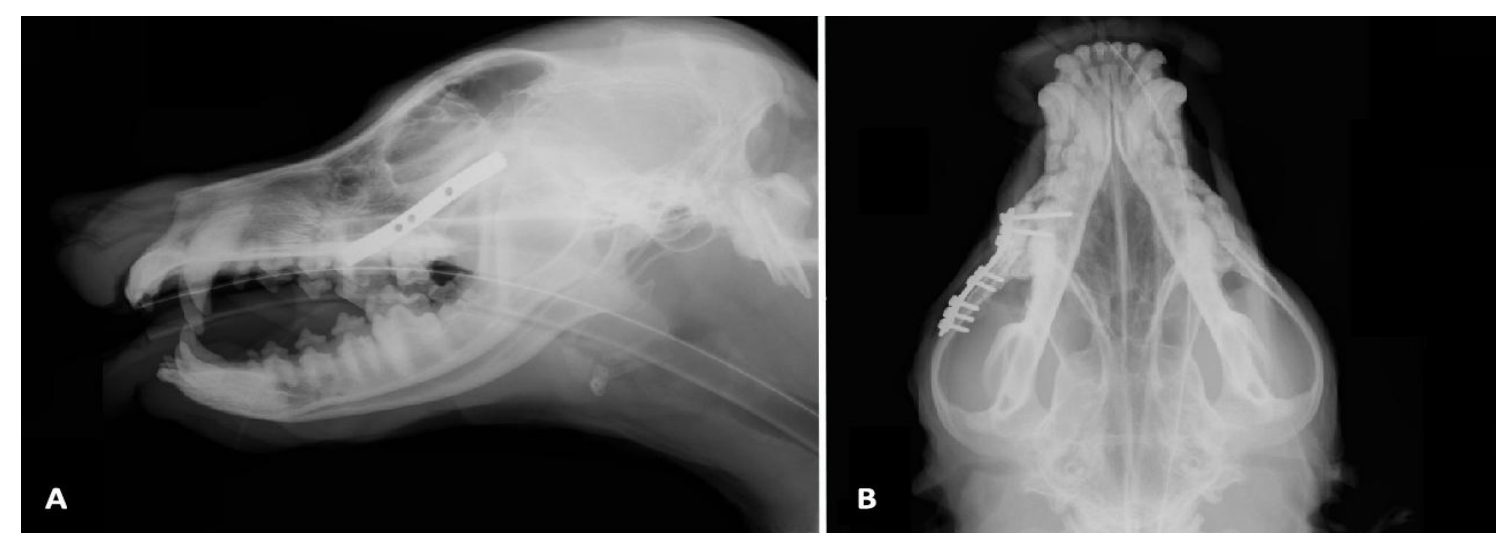

Figure 2. Immediate postoperative radiographs from the previously described fracture of the right zygomatic and maxillary bone reduced by a laterally applied 11-hole VCP plate with 8 screws. Reduction and stabilization of the fracture of the right zygomatic arch and maxillary bone is seen. Lateromedial aspect (A) and ventrodorsal aspect (B).

Postoperative analgesia included hydromorphone $0.025 \mathrm{mg} / \mathrm{kg}$, IV, as needed and meloxicam, $0.1 \mathrm{mg} / \mathrm{kg}, \mathrm{PO}, \mathrm{q} 24 \mathrm{~h}$. Cold therapy was applied to the incision for $10 \mathrm{~min}$ every $8 \mathrm{~h}$ during hospitalization to reduce swelling and provide additional local analgesia. The dog was eating soft food 8 hours following surgery and was discharged from the hospital $36 \mathrm{~h}$ later. A prescription was made for meloxicam, $0.1 \mathrm{mg} / \mathrm{kg}$, $\mathrm{PO}, \mathrm{q} 24 \mathrm{~h}$ for 7 days and tramadol, $3 \mathrm{mg} / \mathrm{kg}, \mathrm{PO}$ up to $\mathrm{q} 8 \mathrm{~h}$ for 4 days following discharge. The owners were instructed to remove all chew toys until full healing was observed and to give only soft food for the next 6 weeks. Rough activity and play with other dogs was not allowed until evidence of healing was identified on radiographs. The patient returned after 10 days for suture removal, the incision site healed without complications. New radiographs were taken 30 days after surgery. The implant was stable and evidence of fracture healing was observed, although radiographic examination is hard to assess due to bone overlapping (Figure 3A, 3B). In-hospital re-evaluation was obtained again at 60 days after surgery. Clinical evaluation was optimal, the implant was stable and no further radiographs were taken, the patient was clinically discharged. 

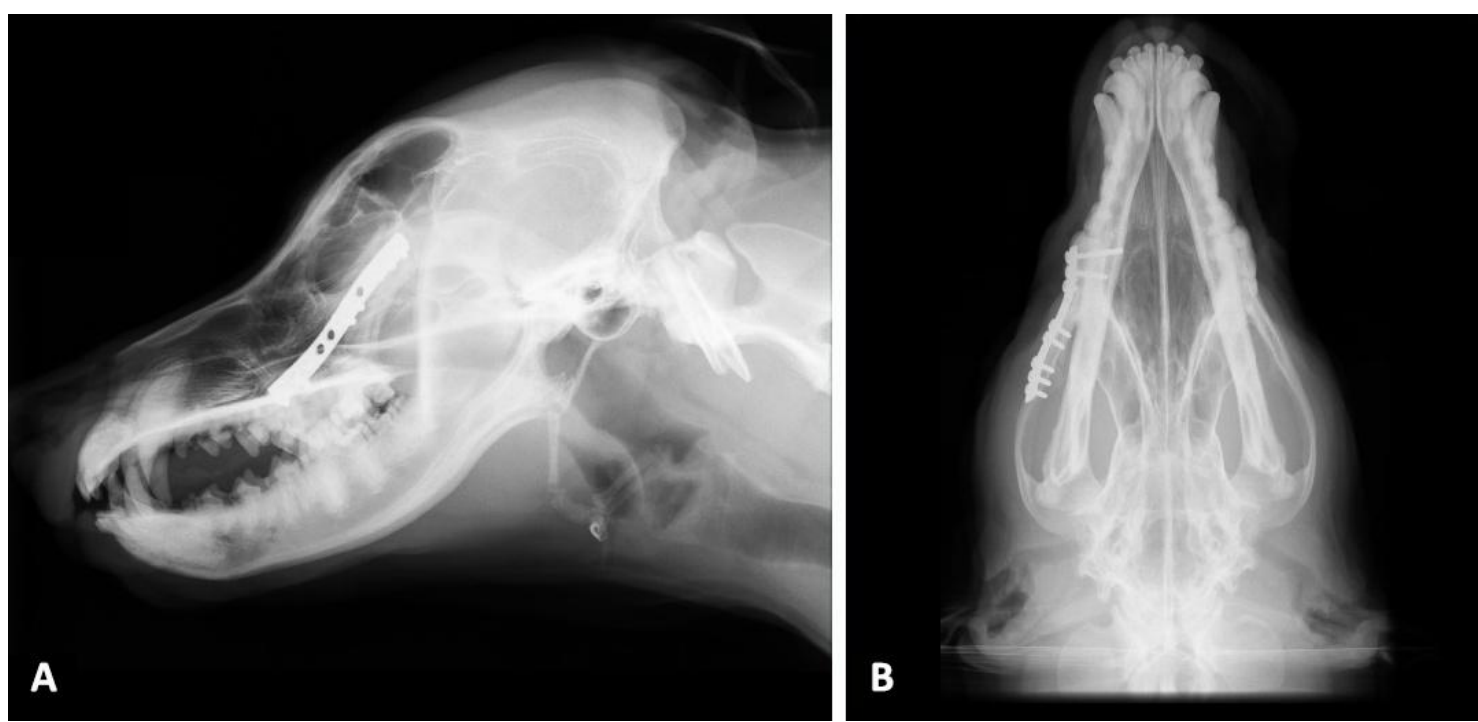

Figure 3. Postoperative radiographs (30 days after surgery). The implants maintained position and alignment with no evidence of infection surrounding the implants. Reduction and stabilization of the fracture of the right zygomatic arch and maxillary bone is seen. Lateromedial aspect (A) and ventrodorsal aspect (B).

\section{DISCUSSION}

Injuries to the head are relatively frequent in companion animals, with reported incidence of $23 \%$ in dogs presented for trauma in a large retrospective study (Kolata, 1980). Fractures to the head can affect the calvarium, the maxillofacial region or the mandible (Scott, 1998). Fractures to the mandible and maxilla are relatively common in cats and dogs, with fractures of the mandible alone making up 3 to $6 \%$ of all fractures in dogs (Umphlet and Johnson, 1990). This type of injury often produces severe disfigurement and distress for the patient (Scott, 1998). Fractures of the zygomatic arch are relatively unusual in small animals (Boudrieau, 2012). Anatomical disparities in skull shape between dogs and humans, as well as the location and importance of the buttresses of the canine skull, may explain a lower prevalence of maxillofacial fractures in dogs and cats compared with humans since the attachment of the maxilla to the base of the skull, seems to have greater bony support compared with humans, despite the absence of the secondary most lateral support adjacent to the orbit, mainly soft tissue (orbital ligament in the dog and cat compared with bony support in humans). Fractures through these buttresses can disrupt the contact with the base of the skull and outcome in malocclusion or even modify the anatomic support of the orbit (Boudrieau, 2004). Treatment must address not only the fracture itself but also the affected soft tissues as well as attempt to guarantee nutrition maintenance (Scott, 1998). Although it is possible to treat non displaced fractures of the zygomatic arch conservatively (Boudrieau, 2012), stabilization of displaced fractures is recommended to repair masticatory function, support of the orbit or for cosmetic purposes. Some displaced fractures, if left untreated and unstable may also result in exuberant callus and even malunion, leading to difficulty opening the mouth and clinical signs that can vary from dysphagia and consequently secondary malnutrition to dyspnea (Hulse \& Hyman, 2003; Laster et al., 2001) Repair of fractures near the caudal aspect of the zygomatic arch must be carefully approached due to the proximity of the facial nerve and maxillary artery and conservative treatment may be the best choice in some cases (Boudrieau, 2012). In this case we opted for surgical correction because the trauma caused a fracture of the maxilla, extending ventrally from the rostro-ventral corner of the orbit to the last molar tooth just cranial to the attachment of the arch and a slightly comminuted fracture of the zygomatic arch just caudal to the orbital ligament. The displaced segment of the arch was depressed medially applying pressure to the globe (see 
picture) causing deviation of the visual axis and exophthalmos. A significant cosmetic defect could also be appreciated with the right side of the face being much less prominent than the left.

Conventional radiography was, for many years, the only diagnostic imaging method available to evaluate animals with skull fractures; however, the skull is a difficult area to study on radiographic examination because of the great range of bone structure variation that occurs amongst breeds and species, besides superimposition of important structures that makes detailed examination of individual parts challenging. To avoid superimposition, many different projections are acquired to demonstrate individual structures or regions within the skull (Owens \& Biery, 1999). Computed Tomography is a more effective, accurate, and useful diagnostic imaging procedure. CT-images are superior to conventional radiographs, not only in the ability to identify the various anatomic components of the skull, but also to determine maxillofacial trauma injuries allowing accurate assessment and treatment planning (Bar-Am et al., 2008). In our case, CT and the 3-D reconstruction allowed the correct assessment of the injuries and preoperative planning to treat the injury effectively. In veterinary medicine skull radiographs and CT must both be obtained with general anesthesia and in this case encountered no problems.

Multiple fixations methods have been described for the treatment of zygomatic arch fractures in dogs, like wires, pins, external fixators and bone plates have all been used successfully (Boudrieau, 2005; Scott, 1998; Piermattei et al., 2006; Schilli et al., 1980). A bone plate was selected in this case because of its excellent three-dimensional stability and its ability to restore and maintain the normal architecture of the zygomatic arch during the healing process. There are reports of the use of miniplate fixation for the treatment of mandibular and maxillofacial trauma in veterinary patients with emphasis typically on mandibular fixation, with little description of fixation of the maxillofacial area (Boudrieau \& Kudisch, 1996; Boudrieau, 2004). These plates, are specifically designed for cranio-maxillofacial reconstruction in humans and are not always available or affordable to veterinary surgeons. The Veterinary Cuttable Plates (VCP) are relatively small plates whose versatility includes options of using different screw sizes, adjusting the length of the plate as needed for varying sized bone fragments, and stacking plates to increase the stiffness of a construct (Brüse et al., 1989). VCP are available in 2 sizes: $1.5 / 2.0 \mathrm{VCP}$ accepts 1.5 and $2.0 \mathrm{~mm}$ screws whereas 2.0/2.7 VCP accepts 2.0, 2.4, and $2.7 \mathrm{~mm}$ screws. These VCP are available in 50 hole lengths and may be cut to the desired length before sterilization or just before application. Identical numbers of holes per unit length allow the surgeon to adjust the plate size based on thickness and width of the plate alone (Hammel et al., 2006; Fruchter \& Holmberg, 1991). With a hole-to-hole distance of $6 \mathrm{~mm}$, they also allow the placement of a large number of screws in a relatively short plate if required. One of the significant drawback of the VCP relative to the human maxillofacial miniplate is its inability to be contoured "in plane". Therefore, complex reconstruction may be difficult if contouring in both planes is required. Fortunately, the zygomatic arch is relatively straight in dogs and a straight plate can often be easily fitted.

The surgical approach allowed the bone fragments to be adequately exposed and reduction was achieved by prying the fragment laterally using a periosteal elevator. The periosteal elevator was inserted medially and ventrally to the zygomatic arch taking care to stay as close to the bone as possible to avoid damage to structures of the maxillary fossa and the orbit. Caution must be exercised to protect the zygomatic branch of the facial nerve, which courses over the caudodorsal aspect of the zygomatic arch. Bradycardia, first-degree atrioventricular block, and prolonged QT interval have been reported in a dog with zygomatic arch fracture, likely due to the activation of the oculocardiac reflex immediately after trauma persisting for 7 days (Ghaffari et al., 2009), this did not happen in this case.

Following contouring, the plate was affixed to the bone using $2.7 \mathrm{~mm}$ self-tapping bone screws. Although fixation in the zygomatic arch itself is relatively straightforward, fixation of the plate into the maxillary bone requires careful planning and attention to details. A thin bone, the presence of the maxillary recesses as well as tooth roots and neurovascular structures make fixation difficult. During placement of the rostral screws, the infraorbital foramen was located by palpation 
and screws oriented as to avoid penetration and avoid damage to the neurovascular structures. Although the rostral screws were placed through the maxillary recess dorsal to the tooth roots; care was taken when drilling and measuring the screw to minimize penetration of the nasal or oral cavity. Adequate soft tissue coverage over the plates and screws is essential to ensure satisfactory healing and prevent infection (Boudrieau, 2012), which was achieved and no infection or problems as wound healing were encountered, or later wound dehiscence resulting in plate exposure occurred, which is a commonly reported complication. The patient returned after 10 days for suture removal without further problems.

For the postoperative evaluation radiographs were chosen for better visualization of the plate position and alignment over the skull bones and to compare with the postoperatively follow ups. Interpretation of these radiographs might be challenging because healing in this region is difficult to assess because the thin cortical bone heals with less callus formation specially when there is good stability in the fracture repair (Scott 1998). Long term follow-up revealed good fracture healing, at 4 weeks recheck the patient had no signs of infection or implant loosening.

\section{CONCLUSION}

Based on our experience, a successful clinical response can be achieved with proper diagnostic and surgical techniques to treat zygomatic arch fractures. Computed tomography is a useful tool to help diagnose subtle fractures. Aggressive pain management in the postoperative period is recommended.

\section{REFERENCES}

BAR-AM, Y.; POLLARD, R.E.; KASS, P.H. et al. The diagnostic yield of conventional radiographs and computed tomography in dogs and cats with maxillofacial trauma. Vet. Surg., v.37, p.294-299, 2008.

BOUDRIEAU, R.J. Fractures of the maxilla. In: JOHNSON, A.L.; HOULTON, J.E.F.; VANNINI, $\mathrm{R}$. AO principles of fracture management in the dog and cat. Davos: AO Publishing, 2005. p.117129.
BOUDRIEAU, R.J. Maxillofacial fractures repair using miniplates and screws. In: VERSTRAETE, F.J.M.; LOMMER, M.J. Oral and maxillofacial surgery in dogs and cats. Toronto: Saunders Elsevier, 2012. p.293-308.

BOUDRIEAU, R.J. Miniplate reconstruction of severely comminuted maxillary fractures in two dogs. Vet. Surg., v.33, p.154-163, 2004.

BOUDRIEAU, R.J.; KUDISCH, M. Miniplate fixation for repair of mandibular and maxillary fractures in $15 \mathrm{dogs}$ and 3 cats. Vet. Surg., v.25, p.277-291, 1996.

BRÜSE, S.; DEE, J.; PRIEUR, W.D. Internal fixation with a veterinary cuttable plate in small animals. Vet. Comp. Orthop. Traumatol, v.2, p.44-50, 1989.

FRUCHTER, A.M.; HOLMBERG, D.L. Mechanical analysis of the veterinary cuttable plate. Vet. Comp. Orthop. Traumatol., v.4, p.116119, 1991.

GHAFFARI, M.S.; MARJANI, M.; MASOUDIFARD, M. Oculocardiac reflex induced by zygomatic arch fracture in a crossbreed dog. J. Vet. Cardiol., v.11, p.67-69, 2009.

GRUSS, J. Complex craniomaxillofacial trauma: evolving concepts in management. A trauma unit's experience-1989 fraser B. gurd lecture. $J$. Trauma Acute Care Surg., v.30, p.377-383, 1990.

HAMMEL, S.P.; PLUHAR, E.G.; NOVO, R.E. et al. Fatigue analysis of plates used for fracture stabilization in small dogs and cats. Vet. Surg., v.35, p.573-578, 2006.

HULSE, D.A.; HYMAN, B. fracture biology and biomechanics. in: SLATTER, D. Textbook of small animal surgery. Philadelphia: Saunders Elsevier, 2003. p.1785-1792.

KOLATA, J.K. Trauma in Dogs and cats: an overview. Vet. Clin. N. Am. Small, v.10, p.515522, 1980.

LASTER, Z.; TEMKIN, D.; ZARFIN, Y. et al. Complete bony fusion of the mandible to the zygomatic complex and maxillary tuberosity: case report and review. Int. J. Oral Maxillofac. Surg., v.30, p.75-79, 2001. 
NEWTON, C.D. Fractures of the skull. In: NEWTON, C.D.; NUNAMAKER, D.M. Textbook of small animal orthopedics. Philadelphia: JB Lippincott, 1985. p.287-295.

OWENS, J.M.; BIERY, D.N. In: CANN, C.C. Radiographic interpretation for the small animal clinician. Baltimore: Williams \& Wilkins, 1999. p.105-110.

SCHILLI, W.D.; EWERS, R.; NIEDERDELLMANN, $\mathrm{H}$. Bone fixation with screws and plates in the maxillofacial region. Int. J. Oral Surg., v.10, p.329-332, 1980.
SCOTT, H.W. The skull and mandible. In: COUGHLAN, A.R.; MILLER, A. BSAVA manual of small animal fracture repair and management. Hampshire: BSAVA, 1998. p.115132.

UMPHLET, R.C.; JOHNSON, A.L. Mandibular fractures in the dog. A retrospective study of 157 cases. Vet. Surg., v.19, p.272-275, 1990. 